\title{
Os recursos hídricos em ambientes geomorfológicos distintos do nordeste brasileiro ${ }^{1}$
}

Water resources in geomorphological environments other than the northeast brazil

Los recursos hídricos en ambientes geomorfológicos distintos del nordeste brasileño

José Falcão Sobrinho Prof. Dr. do Programa de Mestrado Acadêmico em Geografia da Universidade Estadual Vale do Acaraú/UVA. Estágio pós doutoral do Curso de Geografia na UFC. Apoio: falcao.sobral@gmail.com

\section{Marcos Vinícius Ribeiro Mendes}

Técnico em laboratório do Curso de Geografia da Universidade Estadual Vale do Acaraú/UVA. Material de subsídio ao trabalho de conclusão de curso de Geografia.

Edson Vicente da Silva Prof. Pós doctor do Programa de Pós Graduação em Geografia da Universidade Federal do Ceará/UFC. cacauceara@gmail.com

Cleire Lima da Costa Falcão Profa. Dra. da Universidade Estadual do Ceará/UECE. cleirefalcao@gmail.com

\footnotetext{
${ }^{1}$ Projeto com apoio do CNPq: Edital 22/2014. (resultando na pesquisa de estágio pós doutoral do primeiro autor).
} 


\title{
da Alta Paulista
}

\section{RESUMO}

O artigo em questão é fruto da pesquisa realizada na bacia hidrográfica do rio Acaraú, popularmente conhecida por Vale do Acaraú, localizada no Estado do Ceará, pertencente à Região Nordeste do Brasil. A referida área engloba em comum um elevado índice de deficiência hídrica. Nesse contexto, contemplamos os recursos hídricos como objeto de estudo, dando enfoque as cisternas de placas. Objetivamos avaliar os benefícios ou não desse recurso nas referidas áreas a partir da convivência da comunidade com este. O recorte espacial está pautado em três (3) municípios de ambientes geomorfológicos distintos, sendo eles: (Monsenhor Tabosa), um maciço residual úmido e seco (Ipu), no sopé do planalto sedimentar da Ibiapaba, e (Meruoca), localizado no maciço residual úmido. Nesta perspectiva, entrevistamos famílias em comunidades assistidas pelas cisternas, beneficiadas pelo Programa 1 Milhão de Cisternas (P1MC). Inicialmente, pode-se atestar que a construção de cisternas, constitui uma solução bem aceita pela comunidade, contribuindo, dentre outras coisas, com a permanência das famílias em tais ambientes, pois oferta água de qualidade para o consumo humano.

PALAVRAS-CHAVE: recurso hídrico, água, semiárido

\begin{abstract}
The article in question is the result of research carried out in the Acaraú river basin, popularly known as the Acaraú Valley, located in the State of Ceará, in the Northeastern Region of Brazil. The said area generally comprises a high index of water deficiency. In this context, we consider the water resources as object of study, focusing the cisterns of plates. We aim to evaluate the benefits or not of this resource in these areas based on the community 's coexistence with it. The spatial clipping is based on three (3) municipalities with distinct geomorphological environments: (Monsenhor Tabosa), a wet and dry residual mass (Ipu), at the foot of the sedimentary plateau of Ibiapaba, and (Meruoca), located in the massif Residual moisture. In this perspective, we interviewed families in communities assisted by cisterns, benefited by the 1 Million Cisterns Program (P1MC). Initially, it can be stated that the construction of cisterns is a solution well accepted by the community, contributing, among other things, to the permanence of families in such environments, as they offer quality water for human consumption.
\end{abstract}

KEY WORDS: water resource, water, semi-arid

\section{Resumen}

El artículo en cuestión es fruto de la investigación realizada en la cuenca hidrográfica del río Acaraú, popularmente conocida por Vale do Acaraú, ubicada en el Estado de Ceará, perteneciente a la Región Nordeste de Brasil. Esta área engloba en común un elevado índice de deficiencia hídrica. En ese contexto, contemplamos los recursos hídricos como objeto de estudio, dando enfoque a las cisternas de placas. Objetivamos evaluar los beneficios o no de ese recurso en las referidas áreas a partir de la convivencia de la comunidad con éste. El recorte espacial está pautado en tres (3) municipios de ambientes geomorfológicos distintos, siendo ellos: (Monseñor Tabosa), un macizo residual húmedo y seco (Ipu), al pie de la meseta sedimentaria de Ibiapaba, y (Meruoca), ubicado en el macizo Residual húmedo. En esta perspectiva, entrevistamos a familias en comunidades asistidas por las cisternas, beneficiadas por el Programa 1 Millón de Cisternas (P1MC). Inicialmente, se puede atestiguar que la construcción de cisternas, constituye una solución bien aceptada por la comunidad, contribuyendo, entre otras cosas, con la permanencia de las familias en tales ambientes, pues ofrece agua de calidad para el consumo humano.

PALABRAS CLAVE: recurso hídrico, agua, semiárido 


\section{da Alta Paulista}

\section{INTRODUÇÃO}

O Nordeste semiárido se inclui no "Polígono das Secas", dentre suas características se destacam, além das chuvas concentradas em poucos meses do ano, a cobertura vegetal rasteira (caatinga), o embasamento cristalino predominante que dificulta a retenção da água no solo, o forte escoamento superficial (run off), a evapotranspiração potencial acima de $2000 \mathrm{~mm}$, a predominância de rios intermitentes e eventos hidrológicos extremos (secas e cheias) (VIEIRA; FILHO, 2006). No que diz respeito a questão da água na região Nordeste, a mesma tem se tornado uma discussão polêmica. Durante séculos a insuficiência de água ou sua escassez em determinados momentos, foi apontada como a grande responsável pelo atraso socioeconômico da região Nordeste do Brasil, principalmente em sua porção semiárida. Nesse contexto, o Nordeste brasileiro apresenta uma alta variabilidade climática, que está associada à ocorrência de eventos extremos de uma região com aspectos naturais de alta vulnerabilidade ambiental por apresentar exploração dos recursos naturais e, em muitos casos, nos ambientes de maciços residuais úmidos situados ao longo do nordeste seco (Ab'SABER,2003). Ainda nesse sentido, o semiárido abrange a maior parte dos Estados do Nordeste, a região setentrional de Minas Gerais e o norte do Espírito Santo, ocupando uma área total de $969.589,4 \mathrm{~km}^{2}$ (CIRILO, 2008). Concernente à precipitação, é um dos mais chuvosos do planeta, com precipitação anual de 750 embora em algumas áreas a precipitação média não ultrapasse os $400 \mathrm{~mm}$ anuais.

A regulação do uso das águas até o século XIX apenas se verificava para coloca-las a serviço do projeto de exploração econômica, como os privilégios concedidos ao aproveitamento hídrico para construção de engenhos e moendas no ciclo açucareiro ou com o estabelecimento de critérios para a repartição dos caudais no âmbito das atividades realizadas na mineração (FONSECA e PRADO FILHO, 2006).

Salientamos que as formas de uso da água em uma bacia hidrográfica podem ser diversificadas segundo interesses de cada usuário. Diante disso, torna-se necessário que estes usos obedeçam a uma hierarquização de acordo importância/prioridade de abastecimento. $\mathrm{Na}$ bacia do Acaraú, por exemplo, a atividade agrícola realizada a partir da irrigação, representa a maior parcela de consumo de água da bacia, aproximadamente de 85\% (PLANERH, 2000)

Conforme o levantamento de Suassuna e Audry (1995), as águas subterrâneas dos aquíferos aluviais também apresentam, muitas vezes, salinidade e sodicidade elevadas; entretanto, os aquíferos aluviais apresentam mecanismos de renovação e diluições relativamente rápidos, quando comparados aos aquíferos fraturados de cristalino, a depender da sazonalidade das precipitações pluviométricas.

Souza (2000, p,15) destaca que o estado do Ceará ocupa um território de $148.016 \mathrm{~km}^{2}$ entre as coordenadas de $3^{\circ} 46^{\prime} 30^{\prime}$ e $7^{\circ} 52^{\prime} 54^{\prime}$ Latitude Sul e $37^{\circ} 14^{\prime} 54^{\prime \prime}$ e $41^{\circ} 24^{\prime} 55^{\prime \prime}$ Longitude Oeste Gr. Cerca de $92 \%$ de seu território, ou seja, $136.335 \mathrm{Km}^{2}$ acham-se inseridos no semiárido. No contexto nordestino, o Ceará abriga certa diversidade de domínios naturais e paisagísticos. Em relação as suas condições geológicas, essas são variadas, apesar da primazia dos terrenos précambrianos do embasamento cristalino.

Nessa configuração, insere-se a bacia hidrográfica do vale do Acaraú, onde temos como abrangência geral para o nosso estudo. O recorte espacial está pautado em três municípios 


\section{da Alta Paulista}

que fazem parte do Vale do Acaraú, no caso, Monsenhor Tabosa em (maciço residual seco e úmido), Ipu em (superfície sertaneja) e Meruoca em (maciço residual úmido). Conforme Falcão Sobrinho (2008) O vale do Acaraú situa-se no Estado do Ceará, entre as coordenadas geográficas: Latitude Sul de $02^{\circ} 47^{\prime}$ a $04^{\circ} 58^{\prime}$ e Longitude Oeste de $39^{\circ} 40^{\prime}$ a $40^{\circ} 51^{\prime}$.

No que diz respeito a compartimentação geomorfológica do Estado do Ceará, Souza (2006, p.20) afirma que a identificação e delimitação das unidades ambientais resultam de agrupamentos de áreas dotadas de condições específicas quanto às relações mútuas estabelecidas entre os fatores constituintes do potencial ecológico e da exploração biológica.

Desta forma, objetiva-se a presente pesquisa refletir sobre a questão dos recursos hídricos nos distintos ambientes geomorfológicos, a partir da concepção dos recursos hídricos, enfocando as práticas concernentes a convivência com a água.

Partindo desse pensamento, daremos enfoque nas cisternas de placas, que é fruto do programa 1 Milhão de Cisternas Rurais (P1MC), criado em 2003, pela ASA, Articulação do Semiárido. O programa baseia- se na construção de cisternas de placas através da atuação de diversos atores sociais em conjunto com a mobilização e capacitação das comunidades locais. Em relação ao fenômeno de seca no Brasil, há muito tempo, que a escassez de água no semiárido não representa qualquer novidade. Segundo Furtado (1999), o problema da seca no Semiárido nordestino é mais um problema social do que natural, visto ser um fenômeno conhecido e a sua ocorrência, previsível.

De acordo com Andrade (2005), as bases de uma política pública deverão estar focadas nos interesses majoritários da população, e não nos de uma parcela minoritária. Ainda nesse sentido, Furtado (1999) acrescenta que a falta de investimentos em políticas públicas sustentáveis baseadas no paradigma da convivência, sob a qual foi desenvolvida a proposta do (P1MC), condenou as sociedades às piores formas de subdesenvolvimento. Nesse sentido vários programas foram e vem sendo desenvolvidos em busca de alternativas que melhorem a condição de vida do homem no campo, assim viabilizando a fixação do homem no campo, vindo a subsidiar a definição de políticas públicas para essa região.

Em relação aos recursos hídricos que pertencem ao Vale do Acaraú, conforme menciona Falcão Sobrinho (2006), descreveremos das partes mais elevadas as mais baixas, tem-se o vale do Acaraú, a compartimentação geomorfológica que exerce uma influência decisiva nas características dos recursos hídricos. Em seguida um quadro com as distribuições dos principais açudes que estão inseridos ao longo do Vale do Acaraú. 


\section{Fórum Ambiental}

Volume 13, Número 03, 2017

\section{da Alta Paulista}

Quadro 1: Distribuição dos grandes açudes no Vale do Acaraú- Ce

\begin{tabular}{|c|c|c|}
\hline Açud & Município & Capacidade de acumulação $\left(\mathrm{m}^{3}\right)$ \\
\hline Acaraú Mirim & Massapê & 52.000 .000 \\
\hline Araras (Paulo Sarasate) & Varjota & 891.000 .000 \\
\hline Arrebita & Forquilha & 15.600 .000 \\
\hline Jaibaras (Ayres de Souza) & Sobral & 104.430 .000 \\
\hline Bonito & Ipu & 6.000 .000 \\
\hline Carão & Tamboril & 26.230 .000 \\
\hline Taquara & Cariré & 320.000 .000 \\
\hline Edson Queiros & Santa Quitéria & 254.000 .000 \\
\hline Farias Lima & Nova Russas & 12.300 .000 \\
\hline Forquilha & Forquilha & 50.130 .000 \\
\hline São Vicente & Santana do Acaraú & 9.840 .000 \\
\hline Sobral & Sobral & 4.675 .000 \\
\hline Carminha & Catunda & 13.628 .000 \\
\hline TOTAL & & \\
\hline
\end{tabular}

Fonte: COGERH. 2017.

Neste sentido, possui grande influência, devido sua localização, extensão e por possuir vários açudes que servem de abastecimento as populações dando suporte ao seu desenvolvimento.

\section{A NATUREZA E O RELEVO DAS ÁREAS DE ESTUDO}

Estas unidades geomorfológicas permitem-nos a perceber as distribuições irregulares da precipitação, seja no tempo, seja no espaço. As escolhas dos municípios nos distintos ambientes geomorfológicos no vale do Acaraú, pautaram-se da seguinte maneira: I) Monsenhor Tabosa, (maciço residual úmido e seco) II) Ipu (superfície sertaneja de pediplanação e planalto sedimentar da Ibiapaba e III) Meruoca (maciço residual úmido).

As áreas de maciço residuais úmidos e secos do Nordeste tem se colocado tradicionalmente como setores de agricultura sendo significativa para tal ambiente. Dessa forma, as precipitações pluviométricas são bastante elevadas, tendo solos férteis, em meio as superfícies sertanejas de semiaridez (FALCÃO SOBRINHO e COSTA FALCÃO, 2001). No que concerne Às precipitações anuais no Vale do Acaraú, evidenciam-se as existências de uma estação chuvosa e de uma estação seca prolongada. Desta feita, podemos observar os municípios de Monsenhor Tabosa, Ipu e Meruoca, que apresentam oscilações nos regimes pluviométricos. É esta uma das características mais relevantes que serve para singularizar o regime pluviométrico, ao lado da acentuada irregularidade. Verificam-se oscilações na superfície sertaneja, no caso o Município de Ipu, como também nas demais áreas, no maciço residual úmido e seco, ou até mesmo no maciço residual úmido. Vale ressaltar que com uma distribuição da precipitação no decorrer dos 6 primeiros meses do ano, a maior parte da área tem uma estação chuvosa de 3 a 4 meses, fato esse por estarem inseridas no semiárido. Em 


\section{Fórum Ambiental}

Volume 13, Número 03, 2017

\section{da Alta Paulista}

relação a área de maciço residual úmido, no caso, Meruoca, esta registra uma precipitação mais distribuída, comparada ao maciço de Monsenhor Tabosa e Superfície Sertaneja de Ipu.

No município de Monsenhor Tabosa, os índices pluviométricos são bem menor que na serra de Meruoca. Conforme Falcão Sobrinho (2002), a elevação dos totais pluviométricos resulta da combinação de efeitos de altitude e de exposição do relevo às massas de ar carregadas de umidade. As médias de precipitação nesse ambiente permanece quase sempre com $1.000 \mathrm{~mm}$, somente em 2005 que apresentou 500mm, apresentando valores similares com as demais áreas em estudo. Em relação ao Município de Monsenhor (serra das matas), os índices são menores devidos a redução da vegetação, tendo assim um aumento de temperatura. Salientamos que os moradores de Monsenhor Tabosa, nos relataram que os índices pluviométricos eram significativos para a região. No ambiente do sopé do Planalto de Ibiapaba, no Município de Ipu, os registros são consideráveis, quadro esse que se considera normal para áreas onde a temperatura é elevada. O gráfico abaixo referem-se às precipitações anuais dos determinados municípios, entre os anos de 1985 a 2016

Gráfico 1: Total de chuvas acumuladas na Bacia do Acaraú, nos Munícipios de Monsenhor Tabosa, Ipu e Meruoca (CE), 1985-2016

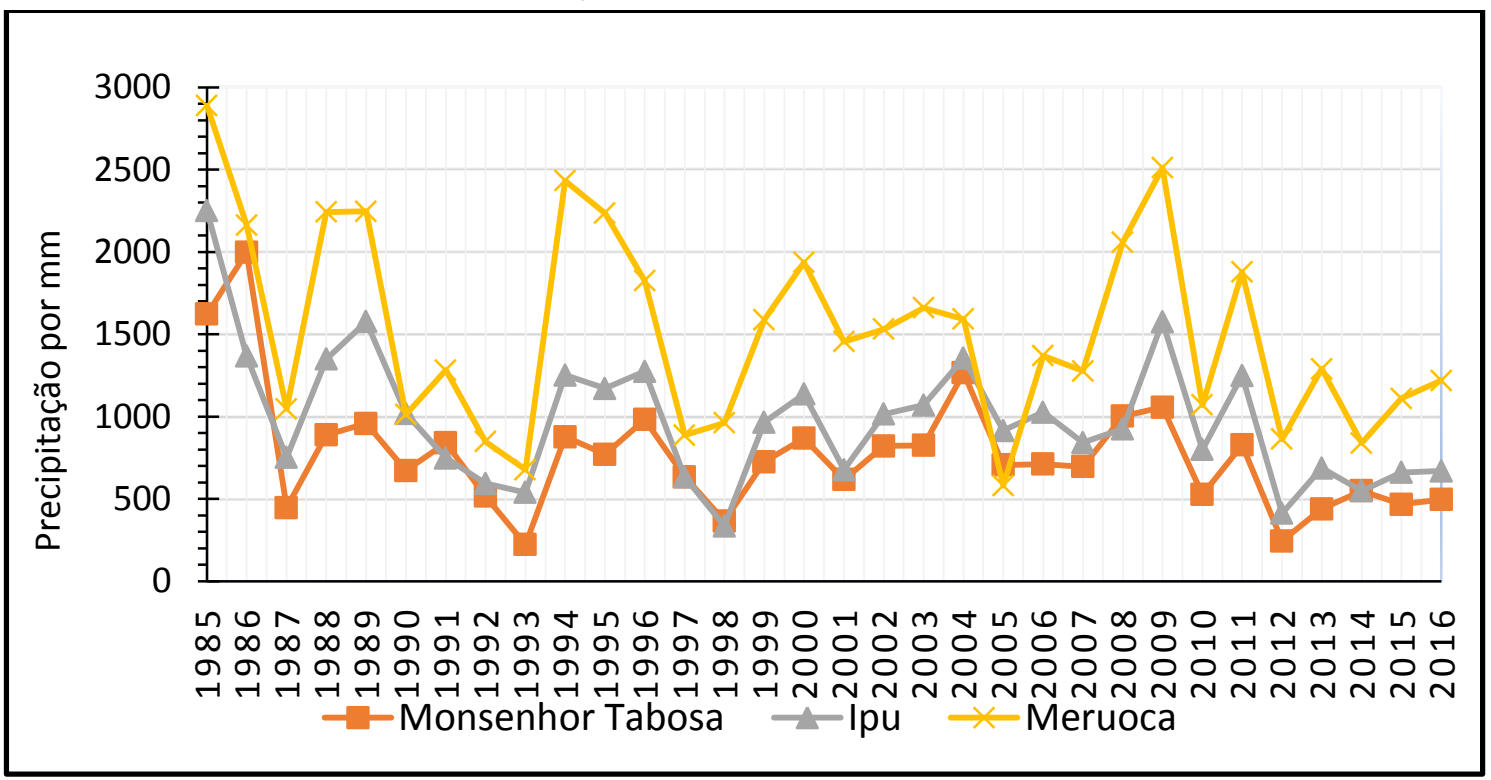

Fonte: FUNCEME, 2017.

\section{MACIÇO RESIDUAL ÚMIDO E SECO DE MONSENHOR TABOSA}

O Município de Monsenhor Tabosa está localizado na porção centro-oeste, com as coordenadas geográficas Latitude (S) 4 47' 22" e Longitude (W) 40 03' 48". Os municípios que estão o seu limite são: Ao Norte, Boa Viajem, Santa Quitéria e Catunda, ao Sul, Tamboril, Independência e Boa Viajem, ao Leste, Boa Viajem e Santa Quitéria, e ao Oeste Catunda e Tamboril (IPECE,2016).

Em uma abordagem de compartimentação geomorfológica, o município de Monsenhor 
Tabosa, na Serra das Matas, está inserido no maciço residual, está em uma área de transição, entre maciços residuais e superfícies sertanejas, (IPECE ,2016).

No caso da serra das matas, prevalece, hoje, a cultura de feijão e milho. Observa-se no cenário da paisagem as modificações sofridas pelas práticas, através de análise empírica. Em relação ao seu relevo residual seco, a serra das matas determina alterações de condições climáticas distinta do semiárido. Destaca-se o solo raso em algumas áreas, com um elevado índice de vegetação de caatinga desbravando as encostas da serra (FALCÃO SOBRINHO e FALCÃO, 2005).

\section{SUPERFÍCIE SERTANEJA E PEDIPLANAÇÃO DO PLANALTO SEDIMENTAR DA IBIAPABA DE IPU}

O Município de Ipú, está localizado na região Noroeste do Estado do Ceará, com as coordenadas geográficas 4 19' 20" Latitude (S) e Longitude (W) 40 42' 39". Os municípios que estão ao seu limite são: Ao Norte, Pires Ferreira, Reriutaba e Guaraciaba do Norte, ao Sul, Ipueira e Hidrolândia, ao Leste, Hidrolândia e Pires Ferreira e ao Oeste, Guaraciaba do Norte, Croata e Ipueiras (IPECE,2016). Em relação à compartimentação geomorfológica, o município de Ipu está inserido em grande parte na superfície sertaneja de pediplanação, e no sopé do planalto sedimentar da Ibiapaba.

Conforme Souza (2006), as superfícies sertaneja embutidas entre níveis de planaltos sedimentares ou cristalinos, com altitudes abaixo de $400 \mathrm{~m}$ e, com acentuada diversificação litológica, amplamente submetidas às condições semiáridas quentes, com forte irregularidade pluviométrica; rede fluviométrica densa, fraca e medianamente entalhada na superfície e com canais fluviais dotados de intermitência sazonal; mosaico de solos com grande variedade de associações, sendo comuns a existência de solos rasos, afloramento rochosos e chãos pedregosos, extensivamente recobertos por caatingas que ostentam grande variedade de padrões fisionômicos e florísticos e diferentes níveis de degradação; uso atual com predominância de atividades agropecuárias.

Nesse sentido, torna-se interessante ressaltar, conforme acrescenta Falcão Sobrinho (2008), que a superfície sertaneja é uma área deprimida localizada entre os ambientes elevados. Sua extensão no estado do Ceará corresponde, a um total de $92 \%$ da área total do estado. No vale do Acaraú, sua dimensão ocupada aproximadamente o mesmo percentual.

\section{MACIÇO RESIDUAL ÚMIDO (MERUOCA)}

O Município de Meruoca está localizado na região Noroeste do Estado do Ceará, com as coordenadas geográficas $3^{\circ} 32^{\prime} 30^{\prime \prime}$ Latitude (S) e Longitude (W) 40 27' 18". Os municípios que estão ao seu limite são: Ao Norte, Massapê, ao Sul, Sobral, ao Leste, Massapê e ao Oeste, Alcântara (IPECE, 2016). As áreas de maciço residuais úmidos do Nordeste tem se colocado tradicionalmente como setores de agricultura sendo significativa para tal ambiente. Dessa forma, as precipitações pluviométricas são bastante elevadas, tendo solos férteis, em meio Às superfícies sertanejas de semiaridez (FALCÃO SOBRINHO e COSTA FALCÃO, 2001).

Nas palavras de Neto e Silva (2012 p, 264) os maciços residuais tratam-se de importantes unidades da paisagem frequentemente observadas por todo o semiárido nordestino com 


\section{da Atta Paulista}

características físicas ambientais distintas das áreas circundantes, que, sobre influência do embasamento cristalino, de origem do Pré-Cambriano.

De acordo com Costa Falcão (2008), em decorrência de seu relevo elevado a serra da Meruoca determinada alteração de condições climáticas, opondo-se ao deslocamento das correntes aéreas, exibindo uma fase úmida (barlavento) e outra, quase seca (sotavento). Favorecendo uma maior precipitação e uma reciclagem de umidade pela constante formação de nevoeiro e orvalho, as chamadas precipitações ocultas. Em relação a bacia do Acaraú, a mesma fica situada na região norte do Estado do Ceará, sendo ampla em seu alto curso e estreitando-se próximo à costa. Drenada exclusivamente pelo rio Acaraú, que nasce na Serra da Mata, o qual nasce na serra da Mata em cotas superiores a $800 \mathrm{~m}$, a bacia do Acaraú desenvolve- se no sentido sul-norte, com aproximadamente $315 \mathrm{~km}$ de extensão, com uma capacidade total de acumulação de $14.266 \mathrm{hm} 3$ e contendo $298 \mathrm{~km}$ de trechos de cursos d'água perenizados artificialmente, (COGERH, 2001). Logo abaixo, podemos observar no mapa a localização dos respectivos municípios nos distintos ambientes geomorfológicos, desde o alto curso até o médio curso da Bacia.

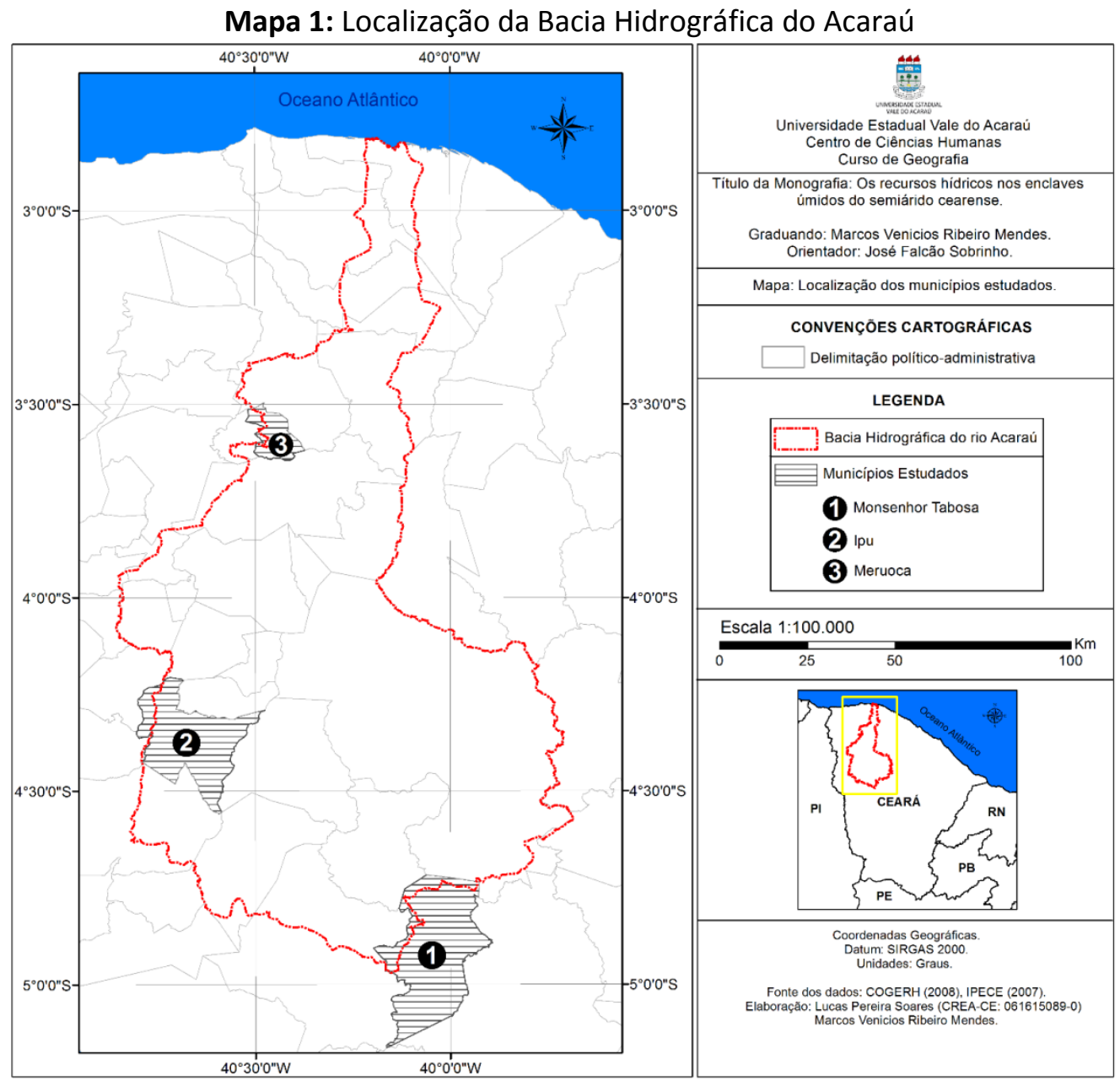

Fonte: COGERH, adaptado por SOARES, Lucas Pereira, e MENDES, Ribeiro Venicios Marcos.2017 


\section{da Alta Paulista}

\section{OBJETIVOS}

Analisar a aplicabilidade das cisternas de placas em ambientes geomorfológicos distintos, a partir da concepção dos recursos hídricos, enfocando as práticas concernentes a convivência com a água.

\section{METODOLOGIA}

Para a realização deste trabalho, o procedimento básico constou de etapas distintas e interligadas nas áreas de estudos. O primeiro momento pautou-se no mapeamento $d$ localização das áreas de estudo, precedidos de sistemáticas atividades em campo. A adaptação do conhecimento da realidade local pautou-se no relatório do Ministério de desenvolvimento social de Desenvolvimento Social MDS (2006), com trabalhos de campo e aplicação de questionários nos distintos municípios. No total foram aplicados 40 questionários em cada área.

No cenário das compartimentações geomorfológicas, essas apresentam diversidades em seu relevo. Para fins de análises empíricas, foram tentados três municípios, no percurso do vale do Acaraú, onde traçou-se um perfil longitudinal. A escolha dos munícipios deu-se da seguinte maneira: o município de Monsenhor Tabosa, nas serras das matas (maciço residual úmido e seco), o município de Ipu em (superfície sertaneja de pediplanação e planalto sedimentar da Ibiapaba) e por fim, o município de Meruoca em (maciço residual úmido). Em relação aos tais ambientes, essas apresentam diferentes condições climáticas e geomorfológicas, posto isso como critério para escolha dos mesmos.

Para efeito de aplicação dos questionários foram estipuladas as seguintes condições: a) condições das moradias; b) características socioeconômicas dos moradores dos domicílios; c) alternativas para aquisição de água.

Considerou-se, ainda, as condições estruturais: a) o acompanhamento das cisternas por quem a implantou (foi ofertado algum curso de manuseio de cisternas para a comunidade beneficiada); b) a avaliação da qualidade da água; c) a forma de reparos que venham a ocorrer; d) o uso atual das cisternas e f) situação dos telhados das casas. As informações acima não constituem respostas isoladas, e sim, o conjunto das informações nos permitem correlacioná-las e permitir reflexões evolutivas aprimoramento do sistema de captação de água para o consumo humano.

\section{RESULTADOS E DISCUSSÕES}

Conforme os resultados alcançados, foi possível verificar que os recursos hídricos melhoraram significativamente na vida das famílias contempladas, nesse viés destacamos as cisternas de placas, por ser mais comum no vale do Acaraú. Vale ressaltar que mesmo estando inseridas em unidades geomorfológicas de características diferentes, a realidade é semelhante. Portanto, a implementação das cisternas tem por objetivo minimizar as irregularidades das 


\section{Fórum Ambiental}

\section{da Atta Paulista}

famílias que compõem o cenário do semiárido, no Vale do Acaraú. No que concerne o grau de escolaridade das famílias, tem-se em média de $20 \%$, aqueles que não estudaram. De acordo com o gráfico 1, as informações correspondem.

Gráfico 1: Nível de Escolaridade

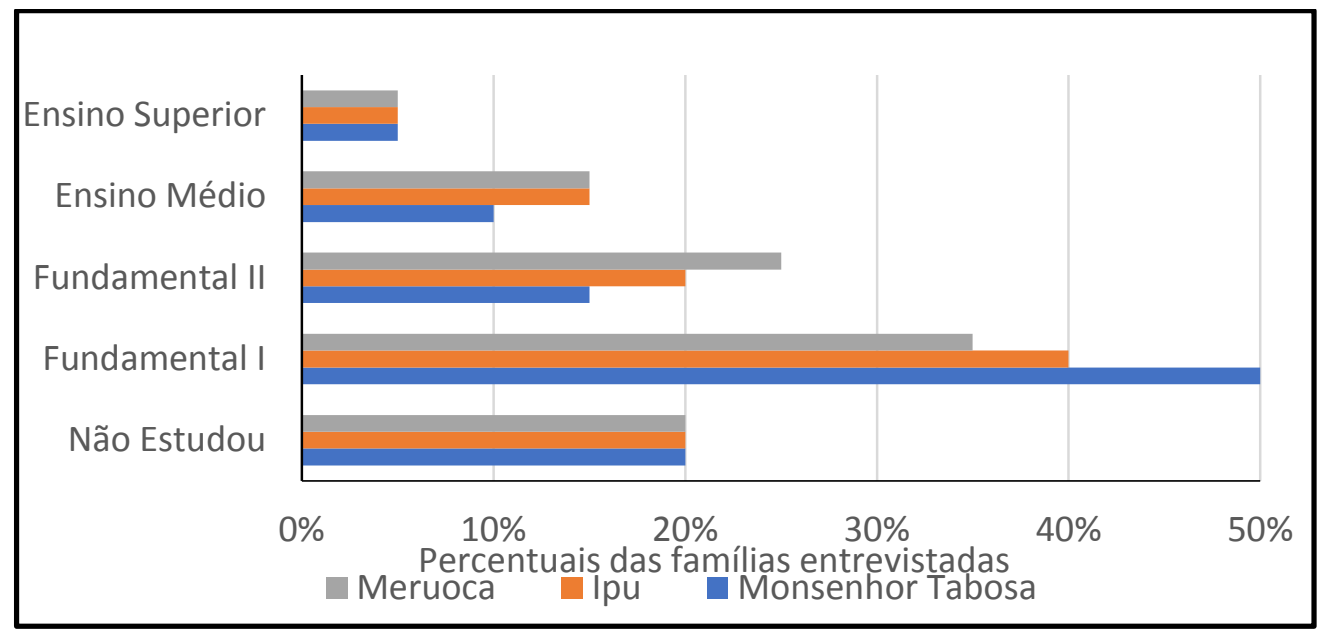

Como menciona o gráfico 2, a maioria das famílias possui renda acima de um salário mínimo, renda essa adquirida através de práticas agrícolas e auxílio governamental, como Bolsa família, Bolsa Escola, Bolsa Estiagem, Brasil Carinhoso, dentre outros, que objetivam fortalecer a economia do local em estudo. $O$ gráfico abaixo concretiza os fatores citados.

Gráfico 2: Renda família

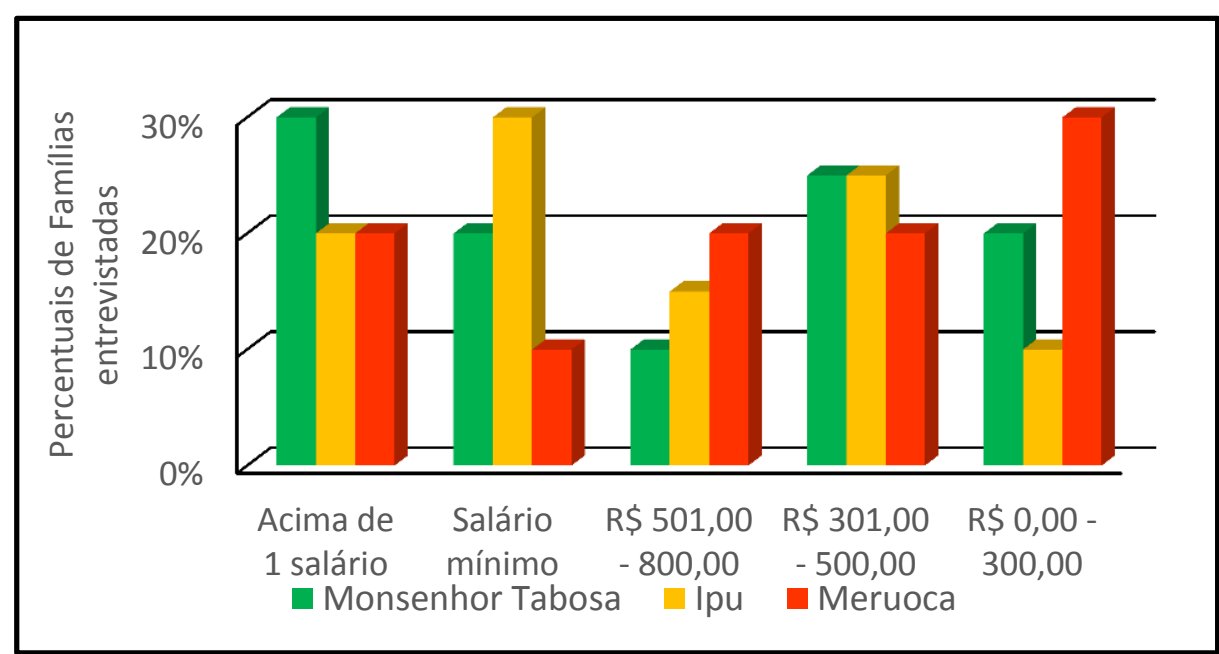

Conforme gráfico 3, Antes da implantação das cisternas a comunidade enfrentava dificuldades para adquirir água potável, apesar de ter um açude público para as famílias, a água não era 


\section{Fórum Ambiental}

\section{da Alta Paulista}

encanada, e as pessoas tinham que se deslocar até o mesmo para retirar água, e quando o nível do açude a água fica imprópria para consumo devido às impurezas. A comunidade relata que no caso das cisternas o armazenamento de água é de qualidade. No gráfico abaixo é demonstrado a procedência da água antes da população ser atendida, prevalecia as barragens.

Gráfico 3: Fontes de abastecimento de água antes das cisternas

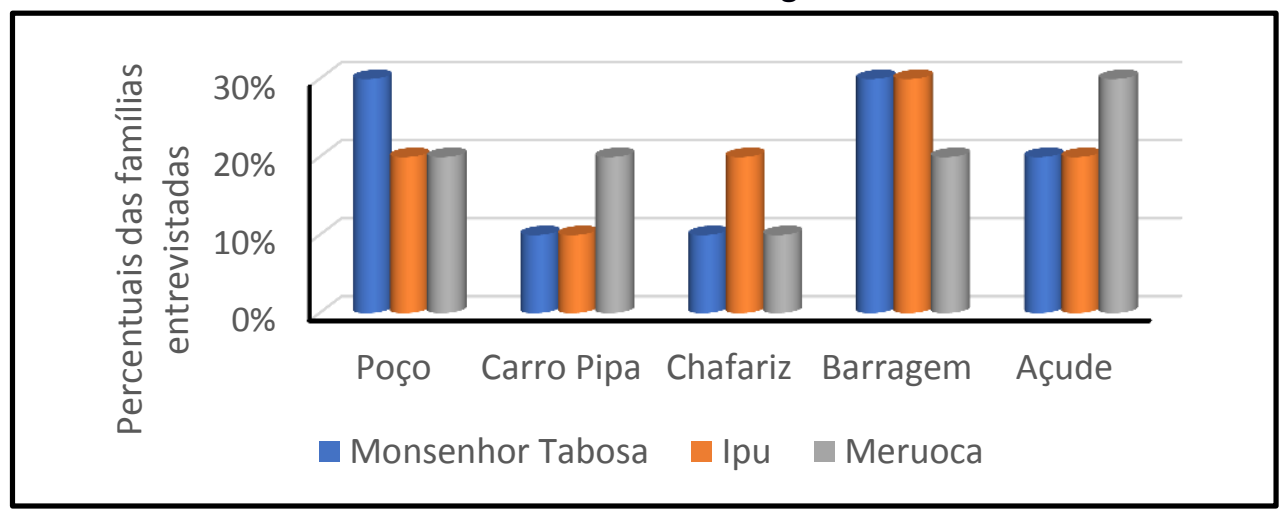

De acordo com gráfico 4, as cisternas como principal fonte, foi observado que as famílias usam a mesma para quase todas as atividades gerais, sendo domésticas e higiênicas, portanto, não seguindo o procedimento das diretrizes do programa 1 Milhão de Cisternas (P1MC), quando aponta que a água desse reservatório é apenas para beber e cozinhar.

Gráfico 4: Uso da água oriunda das cisternas

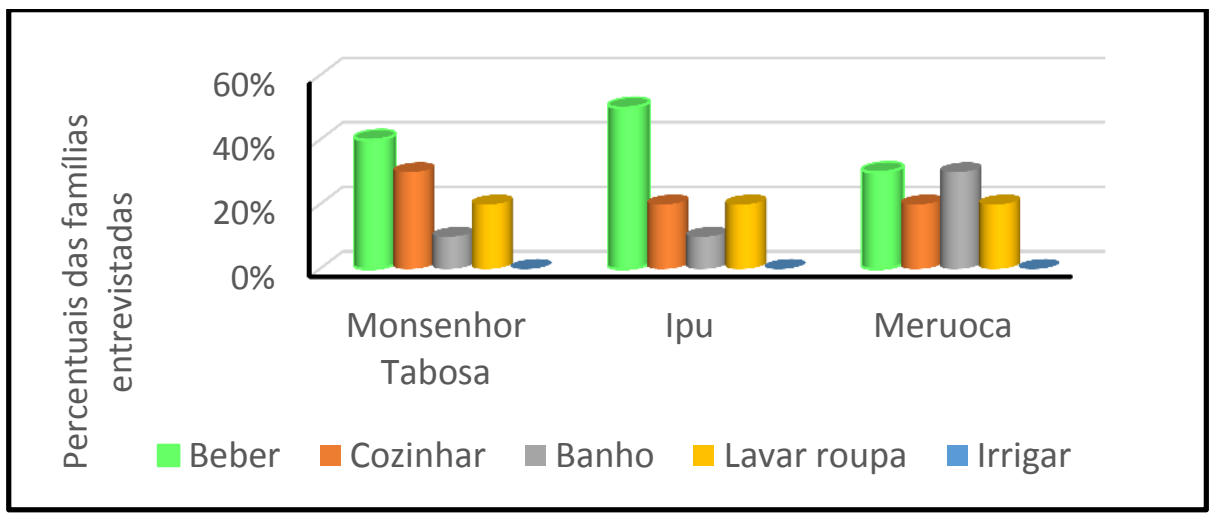

Segundo Cruz (2000) sabemos que a água pode conter impurezas que as tornam impróprias para o consumo. Mesmo com aspectos transparentes não podemos classificar se é uma água de boa qualidade sem passar por tratamentos adequado. A portaria do Ministério da Saúde (MS) n518/ 2004, em seu artigo 4, Inciso I, define água potável como "[...] a água para o consumo humano cujos parâmetros microbiológicos, físicos, químicos e radioativos atendem ao padrão da portabilidade e que não oferecem riscos à saúde " (BRASIL, 2005).

Nem todas as cisternas são abastecidas por água tratada, por isso necessita passar por processo de tratamento. Na ocasião, podemos perceber que desses processos o mais utilizado pelas 


\section{Fórum Ambiental}

\section{da Alta Paulista}

famílias é de Filtragem, onde esse processo consiste em fazer a água passar por substâncias porosas de reter e remover algumas de suas impurezas. Porém, esse sistema não é suficiente para garantir a sua potabilidade, pois a parte dos micróbios é capaz de ultrapassar as camadas de areias dos filtros. (NUNES, 2003). Nesse sentido, o gráfico 5, nos apresenta tais informações.

Gráfico 5: Tratamento da água oriunda da cisterna

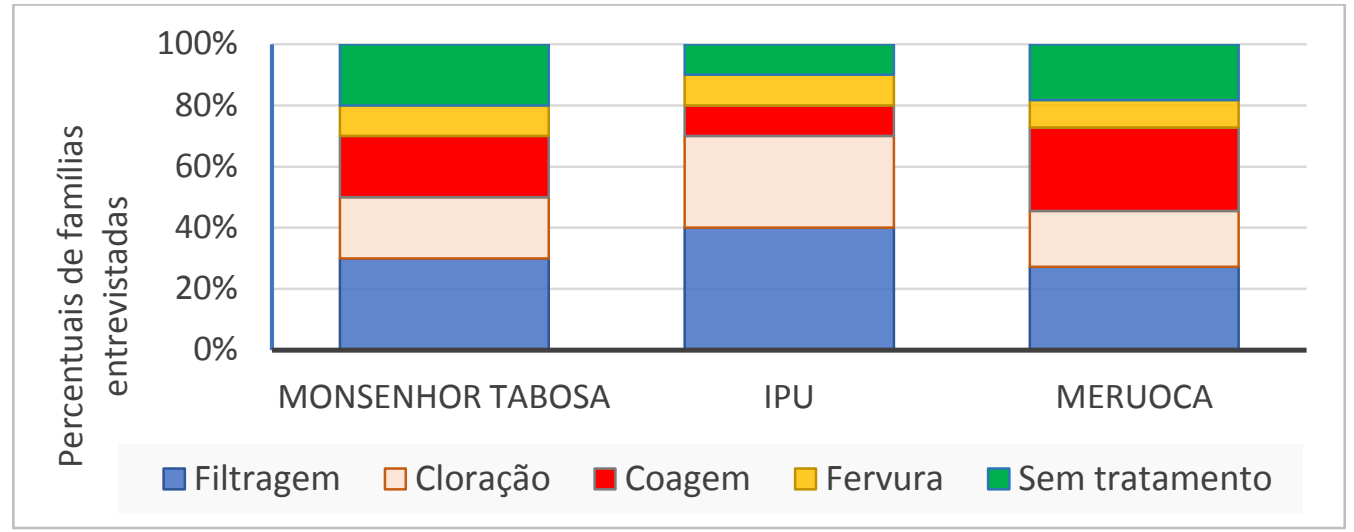

Em consonância com o Gráfico 6, as famílias pesquisadas realizam a limpeza na cisterna pelo menos 1 vez por ano. Vale ressaltar que as mesmas limpam as cisternas por dentro e por fora. Portanto, isso gera um certo cuidado nos seus reservatórios. Salientamos ainda que, os entrevistados utilizam a cal para pintar a cisterna, sobretudo devido a acessibilidade e ao seu baixo custo de aquisição.

Gráfico 6: Disponibilidade de água tendo como fonte as cisternas

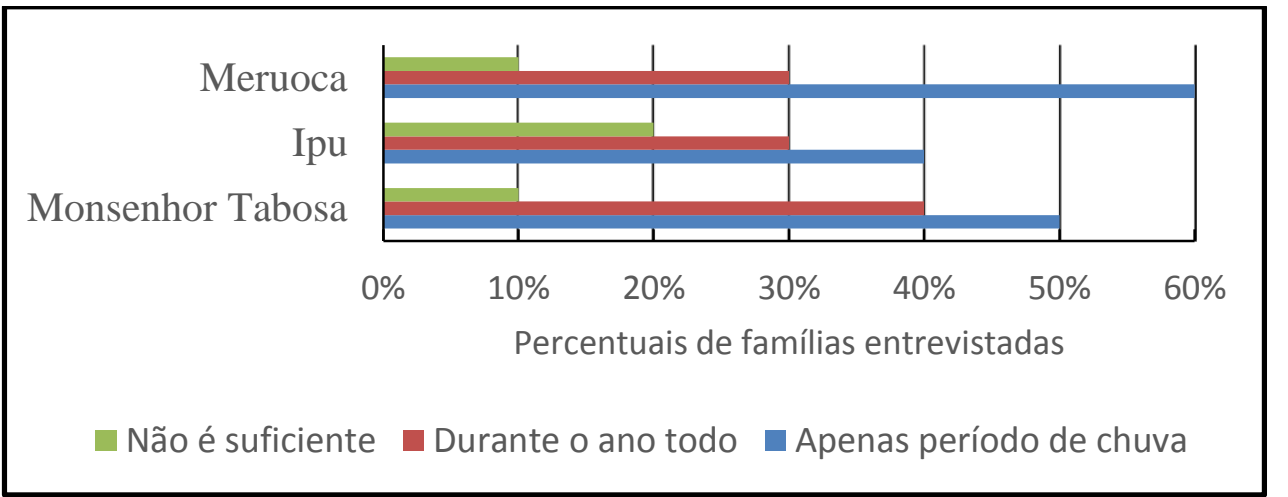

De acordo com o Gráfico 7, constatou-se que a, maioria das famílias possuem condições de moradia com revestimento, ou seja, apresentaram boas condições de moradia. Outras possuem moradias de médias condições, aquelas que sem revestimento em sua casa, e as de barros poucas registram essa situação. 


\section{da Alta Paulista}

Gráfico 7: Material de construção das residências

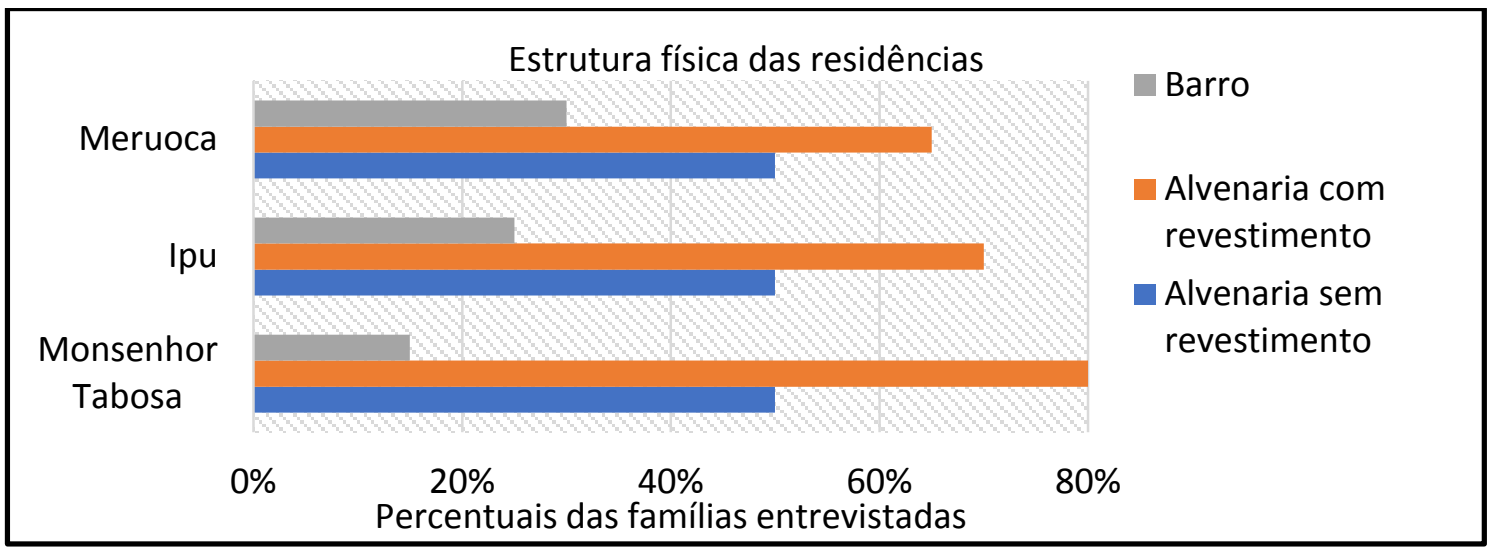

De acordo com o P1MC, a limpeza do telhado é um procedimento fundamental para a qualidade da água, de modo que o telhado deve ser lavado antes de conectar a calha e o cano à cisterna. Segundo, o programa, esse cuidado evita que poeiras, fezes e urinas de animais escorram para dentro dos reservatórios. Na ocasião, constatou-se no gráfico 8, que as famílias se atentam em deixar as primeiras águas limparem os telhados.

Gráfico 8: Tipos de coletas da água

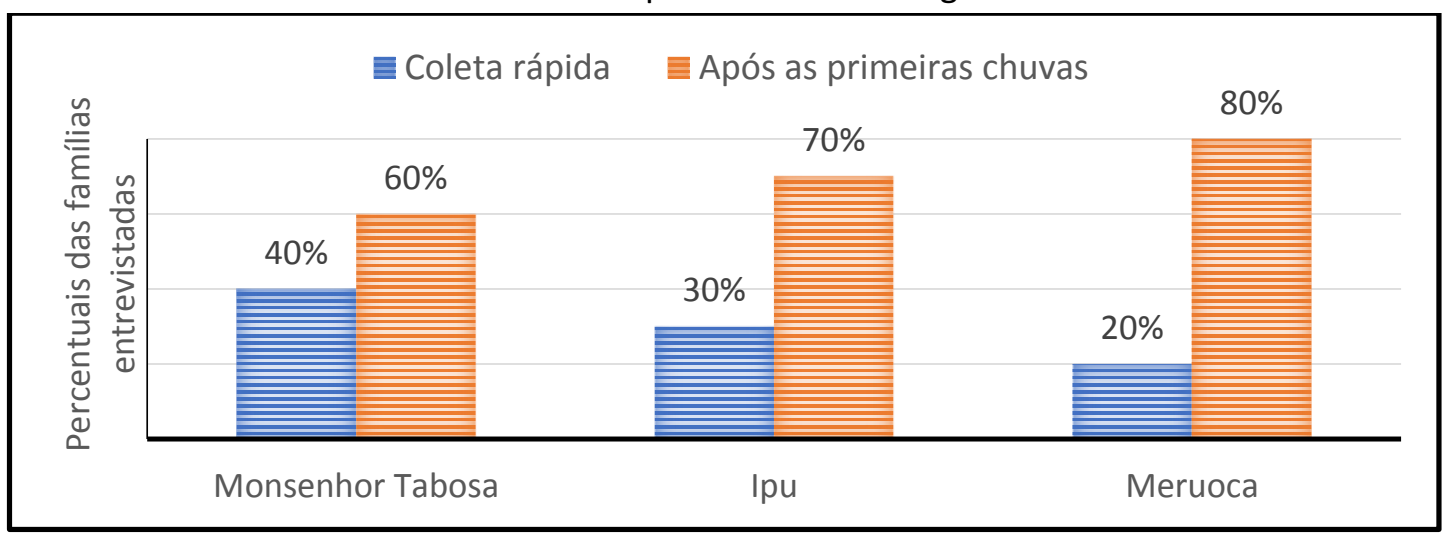

De acordo o gráfico 9, da pesquisa, $20 \%$ das famílias afirmaram que as cisternas foram construídas através de projetos sociais, enquanto que $80 \%$ declararam que as cisternas de placas foram construídas pelo P1MC. Cabe ressaltar que as cisternas construídas por meio de projetos sociais receberam todo aporte estrutural do P1MC através de parcerias. 


\section{da Alta Paulista}

Gráfico 9: Origem da cisterna

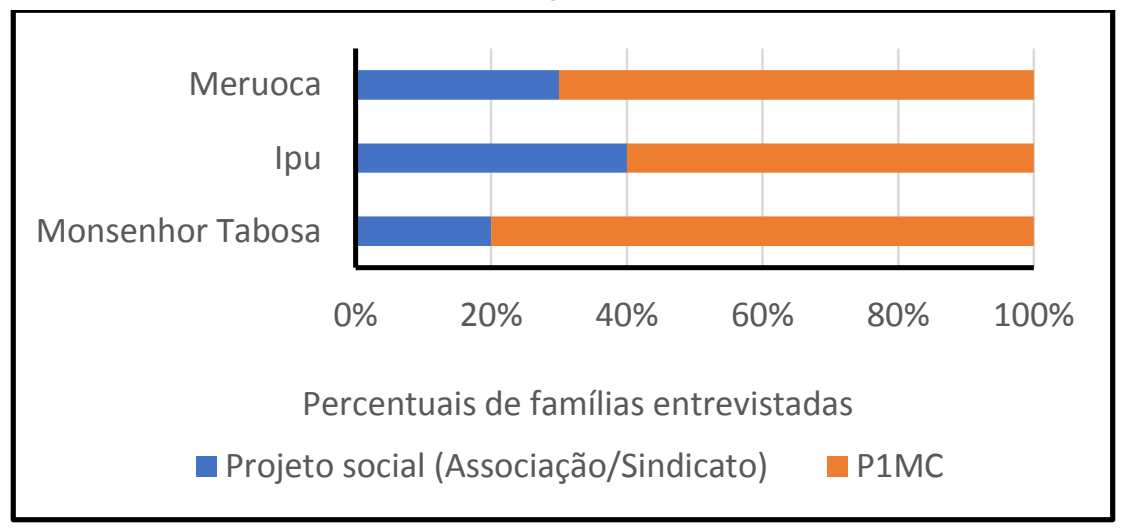

Em relação aos resultados do Gráfico 10, 95\% de famílias pesquisadas afirmaram que a construção das cisternas do P1MC em suas residências proporcionou melhorias consideráveis na qualidade de vida e principalmente na saúde familiar.

Gráfico 10: Colaboração da cisterna para as famílias entrevistadas

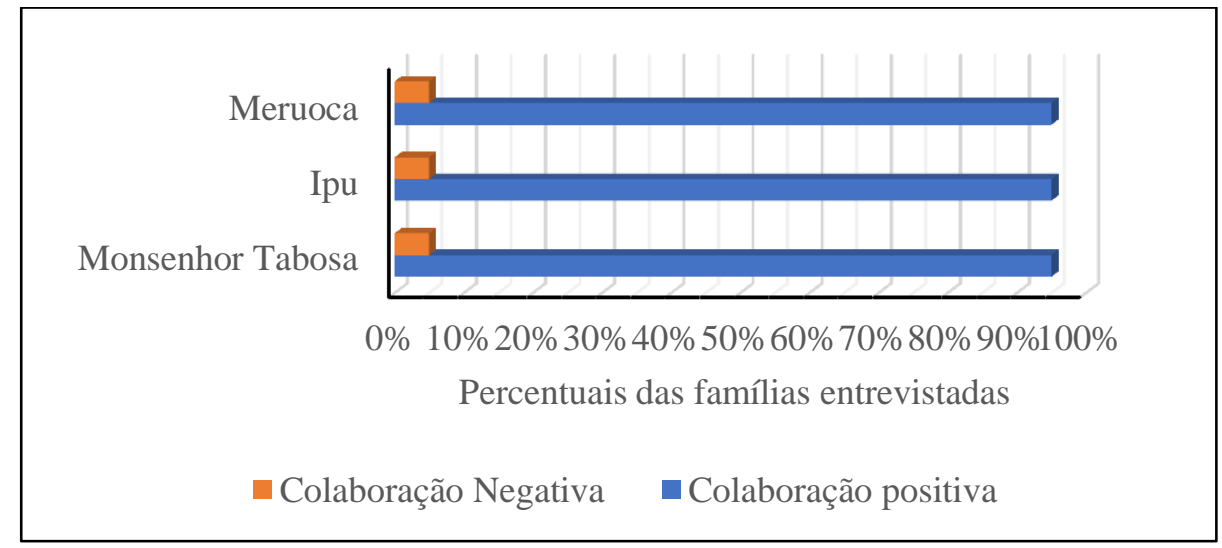

\section{CONSIDERAÇÕES FINAIS}

A pesquisa teve como objetivo refletir sobre a questão dos recursos hídricos nos distintos ambientes geomorfológicos, a partir da concepção dos recursos hídricos, enfocando as práticas concernentes a convivência com a água. De acordo com a pesquisa, no que diz respeito ao nível de escolaridade as famílias possuem apenas a leitura como base educacional.

Todavia, nas famílias sempre tem alguns que sabe ler e escrever. Com referência a renda familiar, a maioria das famílias possuem acima de um salário mínimo. Em consonância com os dados da pesquisa, o abastecimento de água das famílias antes da cisterna era realizado 


\section{da Alta Paulista}

através de recursos hídricos das barragens. Constatou-se que as casas das famílias são construídas de materiais com revestimento, em sua maioria, associando a questão da coleta da água, prevalece o acúmulo de água após as primeiras chuvas. Sobre a suficiência da água, é notória a importância da cisterna, pois após as chuvas permanece água para o consumo no decorrer dos processos meses de estiagem.

No que se refere ao tratamento da água, as famílias cuidam da mesma através da filtragem, mas não possuem discernimento suficiente sobre a limpeza dos filtros. Ressalta-se, ainda, a limpeza da cisterna, do telhado e das calhas sendo práticas comuns realizadas pelas famílias. Em consonância a origem das cisternas, podemos constatar que a maioria é referente ao programa P1MC. No tocante à qualidade de vida, as cisternas proporcionaram melhorias nas condições, sobretudo na diminuição da diarreia e gripe, doenças essas que são comuns nos integrantes das famílias como as mais frequentes antes da chegada das cisternas, como também no ganho de tempo para a realização de outras atividades que eram comprometidas pelas responsabilidades ligadas ao abastecimento de água.

\section{REFERÊNCIAS}

$A B^{\prime} S A ́ B E R, A . N$ Os domínios de natureza no Brasil: potencialidades paisagísticas. $2^{\circ}$ ed. Ed. Ateliê Editorial: São Paulo, 2003.

BRASIL. Ministério da Saúde. Programa nacional de vigilância em saúde ambiental relacionada à qualidade da água para consumo humano. 1. ed. Brasília: Editora do Ministério da Saúde, 2005. 72 p.

COGERH. Programa de gerenciamento das águas territoriais. Fortaleza, 2001. Boletim técnico, Convênio COGERH/DNOCS

CRUZ, DANIEL. O meio ambiente. São Paulo. Ática, 2000

COSTA FALCÃO, C.L; FALCÃO SOBRINHO, J. SOUZA, Raimundo Nonato Rodrigues de.; MOTA, Francisco Alencar (orgs.). Semi- Árido: diversidades naturais e culturais. Fortaleza, Expressão Gráfica, 2008.

CIRILO, J. A. C. Políticas públicas de recursos hídricos para o semi-árido. Estudos Avançados, v.22, p.61-82, 2008.

FURTADO, C. O Nordeste: reflexões sobre uma política alternativa de desenvolvimento. Revista de Economia Política, São Paulo, v. 4, n. 3, p. 5-14, jul. set. 1984. (Centro de Economia Política).

FONSECA, A. de F.C.; PRADO FILHO, J. F. do. Um importante episódio na história da gestão dos recursos hídricos no Brasil: $O$ controle da coroa portuguesa sobre o uso da água nas minas de ouro coloniais. Revista Brasileira de Recursos Hídricos, v. 11, n. 3, p. 5-14, 2006

FALCÃO SOBRINHO, J.; COSTA FALCÃO C.L. Práticas Agrícolas inadequadas acentuam processos 


\section{Fórum Ambiental}

Volume 13, Número 03, 2017

\section{da Alta Paulista}

Erosivo na serra da Meruoca. Ver. Ci. e Téc., Fortaleza, ano 3, n.3.p.25-26, dez/2001

Práticas Agrícolas na Serra da Meruoca. Revista Essentia. Sobral, 2002.

O processo erosivo e a mata ciliar do rio Acaraú na serra das matas (CE). Revista Mercator. Fortaleza, Ceará. Ano 4, 7: 121-134. 2005

IPECE, Instituto de Pesquisa e Estratégia Econômica do Ceará. Fortaleza. 2016

MDS/P1MC - ASA: impacto socioambiental do semiárido Brasileiro, Brasília, 2006

NETO, Manoel Cirício Pereira e SILVA, Neusiene Medeiros da. Relevos residuais (maciços, inselbergues e cristas) como refúgio da biodiversidade no Seridó potiguar. Revista GEONORTE, V,1, N, 4, p262-273, 2012.

PLANERH. Planejamento Estratégico dos Comitês de Bacias Hidrográficas do Estado do Ceará. Fortaleza, 2000.

REBOUÇAS, Aldo C. Água doce no semi-árido. In: REBOUÇAS, A. C.; BRAGA, B. \& TUNDISI, G. (Org.). Águas doces no Brasil: capital ecológico, uso e conservação. [São Paulo]: Escrituras. 2006. p. 481-505

SUASSUNA, J; AUDRY, P. A Salinidade das águas disponíveis para a pequena irrigação no sertão nordestino: Caracterização, variação sazonal e limitações de uso, Recife: CNPq, 1995. $128 \mathrm{p}$

SOUZA, M.J.N. Bases Naturais e Esboço de Zoneamento Geoambiental do Estado do Ceará. Editora FUNECE. Fortaleza, 2000.

Os enclaves úmidos e sub-úmidos do semi-árido do nordeste brasileiro. Revista de Geografia Mercator, ano 05, número 09, 2006

TUNDISI, José Galizia; A água / José Galizia Tundisi, Takako Matsumura Tundisi - [SãoPaulo], Folha, 2005

VIEIRA, V. P.P.B; FILHO, J.C.G.G. Água doce no Semi-árido. In: REBOUÇAS, A da C. et al. Águas Doces no Brasil: Capital Ecológico, Uso e Conservação. 3. ed. São Paulo: Escrituras, 2006. Cap.15, p.481-50 